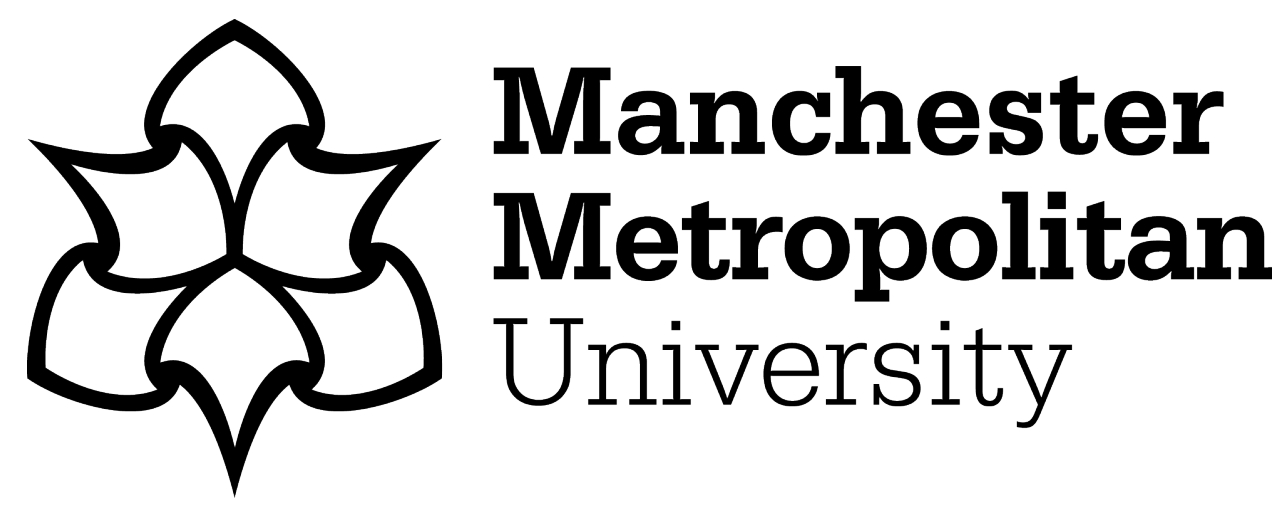

Idriss, MM (2018) Key Agent and Survivor Recommendations for Intervention in Honour-Based Violence in the UK. International Journal of Comparative and Applied Criminal Justice, 42 (4). pp. 321-339. ISSN 2157-6475

Downloaded from: https://e-space.mmu.ac.uk/617933/

Version: Accepted Version

Publisher: Taylor \& Francis

DOI: https://doi.org/10.1080/01924036.2017.1295394

Please cite the published version 


\title{
Key Agent and Survivor Recommendations for Intervention in Honour-Based Violence in the UK
}

\begin{abstract}
This paper concerns recommendations for intervention in honour-based violence (hereafter ' $H B V$ ') as recommended by individuals who face such violence in their everyday lives. Utilising data extracted from interviews conducted with 30 key agents and 8 South-Asian female survivors in the UK, this paper will argue that UK public agencies are struggling to cope with how to respond to $H B V$. This is despite the UK government recognising shortcomings in the support for victims in the House of Commons Home Affairs Committee Report in 2008 (hereafter 'HCHAC'). In particular, participants identified that (a) the police, healthcare and social services are particularly poor at supporting victims; (b) public sector workers require appropriate training and awareness on $H B V$; (c) education on $H B V$ and forced marriages is absent in schools, colleges and universities; and (c) more needs to be done to engage and educate communities about HBV and where victims can access support.
\end{abstract}

Keywords: Honour-Based Violence - Intervention • UK Government - Recommendations

\section{Introduction}

HBV concerns the infliction of violence upon women who are deemed to have brought shame upon their families for reasons (allegedly) involving their sexual behaviour (Welchman and Hossein, 2005; Idriss and Abbas, 2010; Gill, Strange and Roberts, 2014; Julios, 2015). As part of the UK government's response to tackle HBV and socalled 'honour' killings, in 2008 the HCHAC conducted a review of emergency 
responses and intervention. In their Report, the government stated that it 'has made significant steps to improve its response to domestic and so-called 'honour'-based violence and forced marriage over the last few years' (HCHAC, 2008, 6). This includes the passing of legislation and more recently includes the criminalisation of forced marriages (Idriss, 2015). It also includes the extension of police protection and relocation for those in fear of their lives under the Serious Organised Crime and Police Act 2005 (as amended). However, the HCHAC acknowledged that 'the Government's approach to all forms of domestic violence remains disproportionately focused on criminal justice responses at the expense of effective prevention and early intervention' (HCHAC, 2008, p. 6). Specific recommendations were then suggested. With regards to front-line professionals, the Report stated that:

\begin{abstract}
It is essential that front-line professionals who come into contact with victims of domestic violence and forced marriage are equipped to identify abuse and refer the victim to appropriate support. Currently many of these professionals are ill-equipped to do this. We recommend that a thorough programme of accredited training for front-line professionals should be implemented across the board, including teachers, health professionals, visa entry clearance officers, police, judges and magistrates (HCHAC 2008: 7).
\end{abstract}

The HCHAC recommended that there should be better identification of abuse by health care professionals (HCHAC, 2008, pp. 49-51); better responses from and improved training of front-line police officers (HCHAC, 2008, pp. 64-69); that the public should have better awareness of HBV through more informed campaigns (HCHAC, 2008, 2730); and that there should be education programmes in schools about HBV and forced marriages (HCHAC, 2008, pp. 30-38). These preventative measures are vital towards tackling HBV though the HCHAC recognised that education on these issues varies and, in some schools even, is non-existent. There is no 'explicit' statutory requirement for schools to educate pupils about these forms of abuse and some deliberately avoid discussing these issues to avoid offending parents and communities (HCHAC, 2008, p. 
6). The aim of this article is to consider whether the recommendations made by the HCHAC have been acted upon eight years since the Report was first published. It will consider the responses of 38 , mainly female, participants who have directly witnessed or experienced emergency responses and intervention from public agencies, whether as victims or as front-line professionals. The paper will conclude that little progress has been made towards improving emergency responses and developing preventative strategies since the HCHAC Report. Participants in this study singled out experiences of inequality and discrimination in that there were poor responses from the police, healthcare and other professionals; that public sector workers still lack knowledge of $\mathrm{HBV}$; that there is still an absence of educational programmes; and that better-informed information campaigns are needed to engage the public. Whilst it is acknowledged that there are examples of men who experience HBV, these cases are not the focus of this article.

\section{A Literature Review on HBV, Forced Marriages and Intervention}

Philosophers and academics from various disciplines have attempted to define the term 'honour'. At the very outset, there is no single or simple definition of the concept. The term derives its meaning from the Latin words 'honos' or 'honoris' which is taken to mean being brave, courageous and signifying what it is to be a man (Metlo, 2012, p. 32). HBV is a wider term that captures honour killings but also other forms of violence inflicted upon women, such as assault, battery, acid attacks and in some cases, even rape in the name of so-called 'honour'. Honour is a word that varies from culture to culture, region to region and language to language and thus a precise definition is difficult to establish. It has multiple connotations and meanings related to pride, reputation and virtue where young women are brought up within traditional 
environments that polices them (Ortner, 1978, p. 29; Akinpar, 2003, p. 426; Sen, 2005, p. 48). The Urdu word izzat may also be used in this context, which is generally understood to mean 'respect' and good moral character as defined by honour cultures. In trying to fully understand $\mathrm{HBV}$, izzat encompasses the reputation of the individual and the family with the expectation of retaliation when izzat has been violated. Perceptions of women are also demonstrated through the use of the Arabic word Aurat, which has connotations of vulnerability. Aurat, Awrah or Awrat can all be translated to mean 'nakedness' and that intimate parts of the body (and a woman's individual sense of modesty) require covering or protection. 'Honour' is thus perceived as residing within the bodies of women and they are the repositories of honour (Welchman and Hossein, 2005). The notion of honour is also gendered in the sense that men possess the core elements of honour, while woman possess only shame. This produces an inequality between men and women in that women become the sources of honour, but men control and regulate the behaviour of women because women pose a danger to (male) honour. Avoiding shame is important to the overall understanding of HBV (Gill, 2014, p. 2). As Gill states:

Shame (Urdu: sharam) is often associated with transgressions of personal honour, and functions as the opposite to honour: honour is valued highly, whereas shame is to be avoided at all costs. Fears about the loss of personal or family honour shape how individuals act; shame is therefore an effective tool for curbing the behaviour of individuals, and operates as a threatened sanction imposed by a community on those who transgress against the community's norms, traditions and values (Gill, 2010, pp. 219-220).

Gill also explains that 'honour' refers to a person's sense of 'righteousness in the eyes of their community' and that it is 'often employed to ensure that people act morally' if people 'follow what is considered socially good, they are honoured. If not, they are shamed' (Gill, 2012). Thus, honour is attached to an individual person's sense of position within a hierarchical social order - the more honourable they are, the higher 
their position within that social order. It is a socially defined view of a person's individual status and social role - it is based on people being worthy of good opinion of others. Women possess shame on behalf of men and shameful behaviour can affect the reputation of a whole family. HBV and honour killings are thus carried out against women who, it is alleged, have acted irresponsibly and the family, therefore, have no choice but to remove the stain on their reputation. The family unit considers it as the 'victim' and is expected to take corrective action to remedy the situation. Failure to take corrective action may lead the family to be considered irresponsible itself and may then be ostracised by others in the community.

The focus of discussions on HBV is on the on-going behaviour of control and violence, where honour killings are the very end product of a catalogue of serious abuse. HBV in itself can also be very serious and the commonality between HBV and honour killings is the coercion and control exerted by perpetrators. As a final act, perpetrators may kill their victims in the name of honour, but that does not mean control and coercion has not been previously inflicted - typically, there may be limitations of movement or violence well before an actual honour killing takes place. For example, Welchman and Hossein state that:

[HBV]...encompass[es] a variety of manifestations of violence against women, including honour killings, assault, confinement or imprisonment, and interference with choice in marriage, where the publicly articulated justification is attributed to a social order claimed to require the preservation of a concept of honour vested in male (family and/or conjugal) control over women and specifically women's sexual conduct: actual, suspect or potential (Welchman and Hossein, 2005, p. 4).

Similarly, Siddiqui states that:

An 'honour crime' is one of a range of violent or abusive acts committed in the name of 'honour'... 'Honour', in this context, is essentially about defending 'family honour', although this is often extended to reflect the 'honour' of the community. Women who transgress traditional forms of acceptable female behaviour are accused of having brought shame on their family and so besmirched its 'honour'. Failure to be a 'virtuous' woman, such as an obedient and wife, daughter and daughter-in-law, leads to condemnation by the extended family and the 
community at large. In particular, women's sexual conduct comes under strict scrutiny and surveillance. Women are expected to remain chaste or 'unstained' by adultery (and to observe the norms of heterosexuality). Even a hint or allegation of 'immoral' female behaviour is enough to destroy a reputation (Siddiqui, 2005, pp. 263-264).

Meeto and Mirza explain that honour killings involve extreme acts of violence and 'the killing of women for suspected deviation from sexual norms imposed by society' because an 'honour code is believed to have been broken and perceived shame is brought upon the family' (Meeto and Mirza, 2010, p. 42). What differentiates honour killings from other forms of violence is that it is not just intimate partners that carry out acts of violence, but also extended family and community members - multiple perpetrators may be involved (Meeto and Mirza, 2010, p.42; Idriss, 2016). The CPS has explained the 'extended family' is such that those not directly related to the victim will often enforce codes of honour and that one must look beyond the immediate family for those who pose a threat (CPS, 2008, p. 19). The CPS has made reference to the commonality of contract killings and the use of hit men in one out of the nine cases that they investigate, where the primary inciter of violence does not wish to carry out the murder (CPS, 2008, pp. 19-20; see also Johal, 2003, p. 37). Some contract killers may even refuse payment and choose to commit killings out of a belief that they have a duty to enforce codes of honour (CPS, 2008, pp. 19-20).

However, there can never be honour in any concept that uses violence to uphold its value. There have been calls for the term 'honour' to be abandoned - that is, we should not use the word 'honour' in our reference to HBV and honour killings and we should dissociate ourselves from the term (Akinpar, 2003, p. 439). This is because it is considered a misnomer (Meeto and Mirza, 2010, p. 44). HBV is essentially a justification for male violence in order to control women. The term 'honour' praises the crime, making it potentially a more acceptable form of VAW since women are said to exemplify the honour of men and so violence becomes justifiable. Gill echoes similar 
concerns when she argues the term 'honour' 'plays down their severity and belittles the victims' (Gill, 2010, pp. 219-222). The use of 'honour' in this context provides a statement of the crime from the perspective of male perpetrators - by articulating that 'their honour' was affected and at stake (Welchman and Hossein, 2005, p. 8). Academics argue that the term is not gendered enough to explain what really is the central issue - men deciding to kill women (Sirman, 2004, p. 41). In the memorial to Heshu Yones, a victim of a so-called 'honour' killing in the UK in 2003, a campaign slogan was used stating 'There is no 'honour' in domestic violence, only shame!' (Welchman and Hossein, 2005, p. 7; Siddiqui, 2005, p. 263). Similar statements were made at the Shafilea Ahmed Memorial Day in 2015, another victim of an 'honour' killing in 2003. In the literature, one can visibly see feminists using the word 'honour' (in quotation marks) to demonstrate their disapproval of the term for its lack of usefulness.

Acknowledging the word 'honour' also gives legitimacy to the perpetuation of violence and recognises HBV as an 'honourable' deed (Welchman and Hossein, 2005, p. 6). Welchman and Hossein believe that this use of the term also becomes associated with the uniqueness of South-Asian cultures. This highlights a racist and reified application of the term. Media reports often attempt to explain that the root cause of HBV and honour killings is Islam (Anitha and Gill, 2015), with the argument continuing by extension that South-Asian culture promotes such violence (Reddy, 2008; Reddy, 2014). Reddy states that this is 'very relevant within the multicultural context of the UK, where reporting of such crimes has to date only taken place in relation to ethnic minority communities' (Reddy, 2008, p. 309; Reddy, 2014). These representations place $\mathrm{HBV}$ at the door of ethnic minority men as they are alleged to have developed a different set of cultural values from mainstream British culture 
(Reddy, 2008, p. 309; Reimers, 2007). However, there are inherent dangers with making assumptions that reify South-Asian culture. Gangoli et al state:

\begin{abstract}
In the UK and elsewhere in Europe, [HBV and] forced marriage is often conceptualised as a form of violence endemic to, or most relevant to, the experiences of particular ethnic communities, religions and cultures. Within these debates, two (largely unhelpful) ideas are particularly persistent: first, 'clash of culture' between first-generation and second-generation immigrants; and, second, [HBV and] forced marriage as a crime of honour. These ideas work to reify specific minority communities in a way that casts [HBV and] forced marriage as a purely cultural issue which is difficult to intervene in to protect victims. Indeed, a purely cultural lens on [HBV and] forced marriage does not even 'see' victims, since women (and men) subject to [HBV and] forced marriage are constructed as (happily) abiding by their cultural norms rather than as victims (Gangoli et al, 2011, p. 30; see also Anitha and Gill, 2011, p. 126).
\end{abstract}

This extract also highlights the relationship between HBV and forced marriages. Acts of HBV and forced marriages are sometimes viewed as one and the same and there are strong links. HBV consists of acts in response to what is considered to be behaviour that casts dishonour upon the family, yet forced marriages may also occur because families wish to control the sexuality of women or prevent undesirable relationships. Parents may also think about strengthening family links and long-standing family commitments - a commitment to enter two people into marriage may even take place well before those individuals are born and to then retract a promise of a marriage could bring dishonour to the family. Thus, in order to protect 'honour' some may be forced into marriage even if they indicate they do not wish to (Idriss, 2015, p. 688). In the context of intervention, the UK government in June 2014 criminalised forced marriages and breaches of Forced Marriage Protection Orders in a quest to protect victims under the Anti-Social Behaviour, Crime and Policing Act 2014. However, it would appear that the criminalisation of forced marriages has not been a major deterrent since latest figures for 2015 from the Forced Marriage Unit (FMU), part of the Home Office, state that the FMU supported 1,220 cases in that year, having received approximately 350 calls per month in total. Of the cases that the FMU provided support to, 329 (27\%) of those cases involved victims below the age of 18 years, 427 (35\%) involved victims 
aged between $18-25$, the majority of cases (980 or $80 \%$ ) involved female victims, and 240 cases (20\%) involved males (Home Office, 2016). Despite the reform, criminalisation has hindered the reporting of such crimes by those who are afraid to incriminate and see family members prosecuted and/or imprisoned. During the first year of criminalisation up to June 2015, there had only been one successful prosecution in the UK for a forced marriage under the new offence, suggesting that criminalisation has not worked and that other community-based approaches require further exploration (Idriss, 2015). Furthermore, this was not a case one would normally consider to be a 'traditional' example of a forced marriage either - this was a case involving rape, voyeurism, blackmail, forced marriage and bigamy (Guardian, 2015).

South-Asian feminists have long highlighted the problematic issue of intervention for BME women (Wilson, 1978, 2006, 2010). South-Asian feminists have a very difficult job in that not only are they at the forefront of challenging patriarchal power within their communities, but they also have the task of exposing racism and inequalities within national state agencies and support organisations primarily designed to support white women. Given their cultural and religious backgrounds, South-Asian women can find it more difficult to disclose abuse and seek intervention in comparison to white women. While there is a general agreement that all women share a 'collective victimhood', South-Asian feminists point out that this account is not particularly sophisticated when it concerns violence against South-Asian women (Thiara and Gill, 2010, p. 42). Considerations of 'intersectionality' highlight that BME women are often marginalised, multiply-burdened and suffer discrete sources of discrimination because of the 'intersection' of a variety of factors, including race and gender (Crenshaw, 1989). These factors contribute negatively to BME women's experiences of subordination and victimisation not only at the hands of perpetrators, but also at the hands of state agencies 
that are unable to adequately support such women. Intersecting forms of discrimination can create different forms of oppression so that 'women' can be situated in powerful/less ways in comparison to one another (Thiara and Gill, 2010, p. 38). In this context, BME women are placed at a disadvantage to white women. For example, BME women are at greater risk of domestic violence and lethal violence is more prevalent among low-income BME women than white women (Rennison and Planty, 2001; Sokoloff and Dupont, 2005). South-Asian women are more likely to experience severe abuse (and over a longer period of time) in comparison to white women (Gupta, 2003). Others have also concluded that BME women face additional difficulties that increase their vulnerability and ability to leave abusive relationships. This includes their ability to recognise that they are victims of domestic violence; cultural issues relating to 'honour' and 'shame' that can weigh heavily against a South-Asian woman's decision to leave her husband; factors relating to the observance of religion, beliefs or particular religious practices; their nationality and insecure immigration status that may be used against them to further their subordination; language and communicative issues; and community dynamics, where members of the community may seek to dissuade such women from seeking 'outside' intervention (Rai and Thiara, 1997; Burman et al, 2004; Gill, 2004; Chantler, 2006; Anitha, 2008; and Izzidien, 2008). These considerations impact negatively on BME women's overall experiences with state agencies leading some to claim that South-Asian women experience 'double victimisation', where they experience violence by perpetrators and discrimination by state agencies who homogenise their experiences with white women as if all women share a single identity (Razack, 1998; Gill, 2004). Experiences of inequality and discrimination by state agencies continue to mark the lives of BME women and compound their sense of abuse to the extent that some are dissuaded from leaving violent relationships (Thiara and 
Gill, 2010).

The outlook for intervention into HBV, then, is bleak if existing experiences of intervention for BME women is already negative. However, what are the experiences of key professionals and survivors and are their experiences with state agencies any different in HBV cases? Few researchers have investigated the real life experiences related to HBV or have even attempted to gain access to key professionals or survivors through empirical studies in order to gain important insights on appropriate methods of intervention. This is most likely because accessing such a group poses difficulties for a number of reasons, including the fear and the vulnerability of survivors as some relocate and change their identities to escape family members. Accessing key agents might also be difficult because of time and limited availability. These factors contribute to the difficulties of conducting empirical studies into HBV.

In 2010, Begikhani et al published a pioneering and unique research report on Iraqi-Kurdistan on the very issue of HBV (Begikhani et al, 2010). The authors subsequently published their results in a book publication (Begikhani et al, 2015). The authors and their research team conducted one hundred and sixty-six semi-structured interviews with a view towards providing recommendations to combat $\mathrm{HBV}$ within that region and the Iraqi-Kurdish diaspora in the UK. In relation to the UK, the research highlighted 'basic errors in policing' where women and children's lives were unnecessarily being put at risk (Begikhani et al, 2010, p. 118). The authors also recommended the continued need for proactive policies on HBV in the UK; better provision (and resourcing) for specialist support organisations; and the need for a more holistic approach which recognises the complexities of HBV and which requires a more broader social, community and preventative response (and not just a criminal justice response) (Begikhani et al, 2010, p. 129). The authors concluded that there is 'no need 
for further legislation in the UK' because a range of legal remedies is already available to address HBV (Begikhani et al, 2010, p. 131). The authors recommended a more integrated and preventative approach, which includes improving knowledge and awareness among both public agencies and members of the public. The issue of criminal justice responses is particularly interesting because the government has not actively taken steps to address HBV specifically, instead preferring to focus on forced marriages and its criminalisation (Idriss, 2015). Although the HCHAC made various recommendations to improve responses, only the criminalisation of forced marriages has been acted upon with real intent (see Ministry of Justice, 2009; House of Commons Home Affairs Committee, 2011; Home Office, 2012). This was despite the publication of separate empirical research that 'there does not seem to be an appetite for specific legislation' on forced marriage (Gill, 2011, p. 29) and that criminalisation was not strictly necessary (Idriss, 2015). The task of dealing with HBV specifically has been left to voluntary not-for-profit organisations who themselves are finding it very difficult to cope with in a climate of funding cuts and closures. Such threats negatively impact on women's ability to access support and escape abuse (Zosky, 2011). Organisations such as Her Majesty's Inspectorate for Constabulary (HMIC) appear to be the only statutory body to date to make any real concerted effort to understand what key agents and survivors of HBV want from the police service (see HMIC, 2014; HMIC, 2015). Their 2015 Report focuses on HBV and contains useful recommendations for the Home Office and the police to consider.

However, despite these studies, there remarkably remain few studies exploring the experiences of key agents and survivors of HBV. The studies already undertaken clearly overlap with this study, although this study can be differentiated. The basis of this study rests upon the experiences of South-Asian communities as opposed to Iraqi- 
Kurds only, which may yield different experiences. Furthermore, the HMIC report considers only police responses to HBV, while the present study holistically considers a range of responses by various public agencies. Also, while Begikihani et al interviewed thirty-four key agents mainly in the London area, the current study concerns 30 key agent and 8 survivor interviews across Northern and Central England, accessing a variety of participants from different locations and who may have different experiences. This study therefore builds upon the existing literature, although it is original and significant in its own right as it considers the experiences of key agents and survivors on HBV predominantly from South-Asian backgrounds.

\section{Methodology}

The sample is based on qualitative interviews undertaken with 30 key agents and 8 South-Asian female survivors in Northern and Central England. The methodology involved a feminist methodology concerning personal narrative analysis - listening to the accounts and stories of (mainly) female participants and empowering them to 'have a voice' by speaking about their positive and negative experiences of intervention by public and not-for-profit agencies (Kelly, 1988, p. 3). The 30 key agents interviewed were 27 women and 3 men. Of the 27 female key agents, 13 were identifiable as SouthAsian Muslims, the majority who had been born and brought up in the UK (only 5 were born in Pakistan); 12 were identifiable as White or White British females; 1 was a White female Italian; and the final female key agent described herself as Black African. Of the 3 male key agents, 2 were White British males and the other was a British-SouthAsian male. Most of the key agent sample were drawn from refuge or support work (18); others were employed by the criminal justice system as serving police officers of various ranks (8), solicitors/legal workers in the Crown Prosecution Service (2); and 
local authority employees (2). Key agents interviewed were between 23-60 years of age. All but one of the 8 survivors were South-Asian and Muslim (one survivor was a South-Asian Hindu). All were residing in Northern and Central England at the time of interview. Five of the survivors were born in Pakistan, 2 were born in the UK, with the remaining survivor born in India. Many had little or no post-16 education as they were prevented from going to college or had arranged marriages at a young age. Only one UK-born survivor had university qualifications and was in full-time employment during their abuse.

The researcher had no prior contacts with participants and so written correspondence was sent to a number of organisations that the researcher thought would be interested in participating in the research, having researched the names of organisations on the Internet. Northern and Central England was chosen as large concentrations of ethnic minorities live within these areas. After initial meetings with key agents, the researcher (through snowball sampling) asked if they knew others who would be interested in participating. In-depth interviews were conducted with a variety of participants from a variety of backgrounds, ages and disciplines in order to draw genuine and reliable conclusions on their experiences. With the use of an aide memoir and following established protocols on conducting ethical research (including requiring informed consent and respecting confidentiality), interviews were audio recorded and lasted between 1-2 hours each. All interviews were conducted at the location of support organisations and were later transcribed.

Each statement and narrative was examined based on close readings of the transcripts. Comments made by participants were grouped into themes, representing emerging themes, that seemed to be considered important to participants, or those themes and ideas that the researcher thought was particularly important. A scan for any 
connections between topics, what was considered important, what was frequently said (and by whom) and how a theme in one interview connected to another transcript, was also undertaken. The resultant themes were then sharpened and polished into overall themes that were applicable to the transcripts across the board.

\section{Strengths and Limitations}

Interviews with both key agents and survivors were inexpensive in terms of time and cost. Several interviews also took place on the same day at the same location. The expertise and knowledge of key agents provided an invaluable source of information on intervention that simply cannot be obtained from other sources. Likewise, the survivor interviews provided valuable data, especially as accessing this group is difficult for reasons such as fear and vulnerability. This issue was further complicated by the researcher's own background as a South-Asian Muslim male - some survivors rejected requests to participate in the study for the fear of the researcher divulging their ordeals or whereabouts to family members. In relation to limitations, some participants may have understated or overstated the true value of a comment or may have been keen to portray themselves in a certain light because of their vulnerability. There was also a tendency to interview the first key agent available because they happened to be the 'first' on offer for interview. Similarly, key agents selected and recruited survivors who they believed would be ideal for the study. This could potentially affect data reliability. However, these issues were overcome by recruiting participants from a variety of backgrounds and qualitative content analysis was undertaken across the sample, minimising the chances of participants misreporting experiences. Emerging themes were extracted as a whole from the cohort and not individual participants in isolation. 


\section{The Findings}

State Agencies Are Not Meeting the Needs of Victims

Many of the participants stated that they had positive and good working relationships with others tasked with responding to HBV. Some support, refuge and CPS workers explained that they had good relationships with the police:

The relationship with the police is very good, it has seen better days since mid-2000, when the issues of honour-based violence came more and more prominent, 2006, 2007 and 2008... (South-Asian Male Crown Prosecutor).

We work well with the police and forced marriages. They are very responsive, I think...There are problems in general, but generally, it is good...(White British Female Refuge Worker).

Police officers stated that they had good relationships with healthcare professionals at hospitals, where patients experiencing violence often refer themselves to A\&E departments. Healthcare professionals frequently come into contact with victims because of injuries sustained as a result of abuse and are often the first point of call for patients. About hospitals, one police officer said they are in the best position to make referrals because of their direct contact with patients:

Hospitals are very good. If they have an inkling of the case that concerns honour-based violence, they would contact us, they even helped pick up cases concerning FGM. If they are not sure about the case, we will go down and have a chat, and if it's not, it's not, no problems (White British Male Police Officer).

However, a number of key agents were critical of the police and provided examples of their inadequate responses:

The client was unhappy with the way with which the police treated her. She was told to sleep in the office, her and her child, instead of the police station arranging her accommodation overnight, like a bed-and-breakfast, they kept her in the station, and in the morning she decided to go back to her husband. Back to the domestic violence and to the abuser. Obviously, because she didn't get that support, because of the language barrier, the fact that she had a 6 -year-old with her, the police didn't give her any food, their hospitality skills were lacking, she wasn't sure what was going to happen, so she decided to go back home... There was a clear lack of awareness of how to deal with domestic violence in Asian contexts, you can't allow such victims to sit in the main entrance because she's in danger. People in the community might see her. You need to put her in a back room away from sight. It was like [support organisation] had to tell the police the basics on what to do, and it seems funny that the police complain that they don't 
have enough women coming forward reporting domestic violence. With the way this victim was treated, I'm not surprised women are not coming forward to the police if they're not being treated properly. Although this case concerns domestic violence and not honour-based violence, the concerns are still the same. If clients and victims are being turned away or not receiving the appropriate support, they're bound to go back to the abusive relationship or dangerous family settings, which can lead to further violence (South-Asian Female Support Worker).

Communication and the availability of interpreters united many of the survivors in this study. Six out of the eight survivors were not born in the UK, did not have a very good command of English and initially found it difficult to disclose abuse. If the drive to improve victim disclosure is genuine avenues to allow women to make disclosures must be available. This includes employing more bilingual workers within public agencies who are able to speak the same languages as victims. Speaking the same language will make it easier for victims to come forward and disclose abuse. Several of the survivors explained that a lack of interpreters had made it difficult to for them to disclose abuse and one recalled her experience of the police asking her daughter to translate, which she found to be wholly inappropriate:

\begin{abstract}
...with police, I have just one issue...I call police straight away, because he's [i.e. her husband] doing something. Police came, that time I'm not speaking properly, English. And I'm nervous as well. I'm shaking. Police says: 'I need to information. What's happened? Why your husband smacking you?' My daughter, she's know well with the police, before, she's scared as well. And police asking. I said: 'You can bring anybody, I call my friend, she coming, because my daughter is not coming in front of police, talking, my all daughters upstairs. And police asking my daughter: 'You translate'. That's wrong, isn't it? Some secret I keep from my daughter, I can't tell. That's wrong. I said loads, I'm going counsel meeting, I said loads of times, police need translator. If you come Asian family's house, you can come back to interview me. Police say: 'There's no Asian police officer at the time, what shall I do?' It's not my problem that time, I'm nervous, I don't want daughter to involved and tell all my story. After, she crying. She'll broke down. 'Oh my god mom, you're suffering that much'. That's wrong, that's issue. That's issue only me with police (Survivor).
\end{abstract}

Support workers validated accounts of the police asking children, husbands and other family members to act as translators on victims' behalf:

I think so, yeah, first of all, they have interpretive issues, haven't they, yeah, they've used like children really in the past, eight-year-olds, six-year-olds, as interpreters, or they've actually used the husbands, the perpetrators themselves [laughs], actually go into a house, even in this day and age, and talk to a perpetrator who says: 'Oh no, she's got mental health problems, so, we are just trying to calm her down, it might seem I'm restraining her, but I'm just trying to calm 
her down, and during that, she thought I was violent, that's why she's rang the police'. And because she does not know the language, she doesn't know what's going on at all, she's just nodding away, and has more batterings afterwards, because: 'You rang the police', so it's really hard (South-Asian Female Support Worker).

Other key agents revealed tensions with other professionals and, in particular,

highlighted their concerns with GPs and hospitals. There were instances where support

workers had suspicions about South-Asian GPs and that some breach confidentiality by

disclosing to the patient's family that their daughter has reported abuse and is seeking

help from the police, support services or is considering fleeing home. One support

worker said:

It is compromised and I'm always reluctant to allow victims of forced marriages and honourbased violence to register with surgeries, because it can lead to the previous surgery to know where they have gone and if they have any family member or friend who can get access to the files, then it is dangerous...We are still struggling and trying to find a way where we can get victims registered with new surgeries wherever they go. But the suggestions are either that previously we have had doctors records sent to solicitors, then the solicitor sent it to me, so they don't know where it has gone. Or the other idea is that there has to be a totally new protocol set up for victims of honour-based violence. So nobody knows, somehow, where she's gone. It can't be disclosed (South-Asian Female Support Worker).

Others raised concerns about hospitals and, in some instances, were very critical of them for failing to identify cases of abuse:

We had a lady and her husband pushed her down the stairs. Her husband took her to A\&E because she was in a lot of pain. At A\&E, the doctors and nurses asked: 'How did you get the pain?', she said she fell down the stairs. She didn't mention anything about domestic violence, or her husband pushing her down the stairs. Obviously not, because the husband was with her. She wasn't going to say to the doctors: 'Oh, my husband is with me, he pushed me down the stairs'. It just does not happen... Obviously, the A\&E staff are not trained up because if they were trained up, they should have taken her to a different room, got a different doctor, spoke to her when she was isolated, they should have spoken to her in private, they should have provided her with an interpreter. This type of case should have rung alarm bells for A\&E - at least be suspicious - doubt should arise if there is a breakage and it has not been explained adequately...A normal practice should be in place to ascertain any injuries and this should be undertaken in a private place. 'Is there anything you want to share with us?' (South-Asian Female Support Worker).

State Agencies Lack Basic Awareness and Training on HBV 
Public sector professionals still lack general awareness and an understanding of HBV

or the particular sensitivities that can arise in such cases for BME women. Support

workers and police officers were, for example, very critical of social services:

[Laughs] We've had several issues with social services in the past when we are dealing with our clients (South-Asian Female Support Worker).

Social services don't quite get it yet, I don't think. The people I've tend to deal with don't get it. Sometimes, you feel that you are talking in a completely different language to some people, that's how it feels sometimes (White British Female Police Officer).

One support worker explained a case of a woman who had experienced domestic violence and had contacted social services. Her husband was violent, had mental health issues and her in-laws condoned her abuse. When she notified social services about her abuse they advised her to leave home with her children:

She then left, went to social services and social services rang [support organisation] and they didn't have a clue what to do. The victim had three children, they were tired, hungry, had no lunch, nothing, and separate people interviewed her on two or three separate occasions. I complained: 'Have you thought about feeding her?' At the end, it was 8pm, I was still with her, I wanted to sort out refuge accommodation for her. The refuge that was provided was a refuge in a non-Asian area, no Asian shops, no halal meat for her to get and there was a language barrier because she couldn't speak any English, three small children - and social services said: 'We will take you to this refuge'. They also said 'Shall we put you on the train?' I said: 'This time, on the train, with luggage, three small children, no language, can't read the signboards, in a foreign town, somebody might potentially see her?' It's traumatic enough when you leave a relationship, with safety issues more than anything, to be left alone, is another thing! You need that support. Eventually, the client went back to social services, at 9pm, she said: 'I'm not going there, no Asian shops, no other Asian person, I can't buy any halal meat', and so social services said: 'Okay, shall we take you back to your house'. All day, social services kept her and then they wanted to take her back home. What about her safety? The family will ask her where she has been all day. What will social services say to them? (South-Asian Female Support Worker).

These accounts represent a lack of awareness that key agents put down to poor training.

Survivors validated these experiences, explaining that public agencies had demonstrated ignorance about the additional difficulties BME women face. One survivor had escaped an attempted forced marriage by her father and the police had unwittingly disclosed the city of her location after he had reported her 'missing': 
...then I got a phone call from [support worker]...I got a phone call from her saying: 'The police have told your family', because originally, they reported me as missing, but a police officer came and spoke to me and I told them I left on my own free will, it was my dad who reported me as missing. But then they told my dad, and I don't know how, that: 'She's got an appointment at the job centre in [city]'.

MMI: That was potentially very dangerous, wasn't it?

At that point, when they told me that, I can't even explain to you how I felt, cos every time I heard a noise, I thought: 'Oh my God, that's them'. Even though they didn't know where it was, but then like, [city] was so small and I just thought, if I was out and about, like I did go, like, a few days before I did go to the job centre, what if, like, someone recognised me, they showed my picture, anything. And every noise that I heard, I'd think: 'Oh my God, that's them'. But I think I only stayed there for a couple of more days, and they moved me back here, erm, and I think that was the main thing for me...even till this day I don't understand how my dad found out I was in [city], and, you know like, why they told him, for me like, knowing that, like I was so scared, I just thought, like, if he sees me, he's gonna kill me. Cos I'm gonna bring shame on his family, everything, like within the community, everybody there they're gonna know that my dad's a really proud man, so I thought that: 'That's it, as soon as he see's me, he's gonna kill me and [mumbles]', obviously that didn't happen, but then, like, but knowing that he could find where I was, it was the most scary thing...even till this day, I don't know why they did it...I know [support worker] tried chasing it...but I got nothing back from them...(Survivor).

Another key agent was particularly scathing of the police for their lack of understanding of HBV:

When I was dealing with a client once, a white female police officer was present and said: 'Shall I ring her family to let them know she is safe?' I said: 'No! She's an Asian girl running away from her family'. There is a lack of awareness. And lot of agencies with white women workers still do not understand the issues surrounding Asian cultures (South-Asian Female Support Worker).

Conveying such information to families could prove fatal as families may try to use that information to locate and harm victims. Other key agents echoed similar concerns explaining that public agencies have not properly trained staff about violence experienced by BME women and how inappropriate responses can force women to return to abusive relationships:

One Arab woman went to a white refuge - the refuge had an open drinking policy and on the first night, she had lager spilt on her, so she decided to go back home to the violence. A lot of white refuges have not sorted themselves out yet when dealing with BME women (South-Asian Female Support Worker).

Depressed, crying, coming in with their children, women suffering abuse for 20 or 30 years, as an Asian, they find it culturally difficult to leave home, with the stigma and everything else attached to that - especially the expectations of being an Asian woman (South-Asian Female Support Worker). 
We do training about awareness of honour-based violence and the whole thrust of the training is to respond appropriately to the needs of the victim - it is not that hard (White British Female Support Worker).

The nature, characteristics and dangers of HBV must also be conveyed to all public sector workers who come into contact with the public. A failure to recognise these issues could prove catastrophic for victims:

\begin{abstract}
The first contact is the most important contact. When a victim comes forward, the ten-eleven women that I saw, all of them said they were never ever allowed out of their house. So how do we get a message to them that what is happening to them is criminal - signpost - how do we do that? Some of them said: 'We have got children, the only time we are allowed out is when we drop our children off to school', so there is a 15 minute window of opportunity, if the teacher, or somebody in the school, took it upon themselves to ask, to seek a disclosure, even doctors, nurses, GPs, receptionists, security guards at universities, it goes back to the point that everyone has a role to play, and the first point of contact is the most important - health professionals, doctors, nurses, midwives need to think there is something at work here and I need to do something about it. Then they need to know where to go with that information and to do it quickly. Schools, local authorities, statutory organisations, there needs to be that level of specialism and the level of understanding, but at all the various levels (South-Asian Male Crown Prosecutor).
\end{abstract}

Do you know whether the man on the security desk knows what to do if someone appears at their desk and states: 'I am about to be forced into marriage' or 'My family want to kill me'. Most will look quizzingly. Do you know that most of these girls, victims have never been out of the house and they see a big building or town hall or university and think: 'Somebody in there might be able to help me'. And then they go into security and ask for help and the man looks at them blankly - that is a missed opportunity and with some cases, sadly, where at 10am the girl is told she is in danger and by midday she is dead. The level of escalation and risk is faster than any other crime. In domestic violence, there is usually a constant pattern, but in these kinds of areas in honour based violence, you are being forced into marriage, a girl is discovered to have a boyfriend, two hours later, she is dead. So, if you have got that small window of opportunity, we need to be sure that there is a basic level of understanding at every statutory local authority building, but they know what to do, where to signpost, and that someone somewhere can take action on that part (South-Asian Male Crown Prosecutor).

One survivor who had been forced into marriage validated the above account. She explained how she had hoped to disclose her abuse to the local hospital because of the injuries she sustained from her husband. However, the doctors and nurses did not seek a disclosure:

The time when he [i.e. her abusive husband] smashed a can a beans on my hand and I had three fractured knuckles, and they said: 'How have you done that?' and I said: 'Well, I caught it in the fridge door'. But that's ridiculous, because a fridge door could never do that. I thought somebody was going to say: 'No, a fridge door will never do that'. No, it was fine. They just 
put the splints on and...I said to myself: 'I don't want them to believe me'. I said: 'I'm not going to say the door, I'm gonna say the fridge door'. There's no way on earth you can end up with a hand like this in a fridge door. And I thought somebody is going to say: 'That doesn't happen in a fridge door'. If they pressed me, I would have told them the truth. If somebody had been just prepared to say: 'Well actually, no that isn't, those injuries are not possible from a fridge door, somebody putting your hand there and repeatedly slamming the fridge door is a different thing, but that wouldn't be counted as an accident, would it? So would you care to show how that happened?' But nobody questioned, nobody ever asked. It's lack of knowledge and lack of awareness, we keep on going back to that. It's 'Their [i.e. South-Asian] things, this is what happens in their homes, leave them to it' and that's got to stop (Survivor).

Key agents suggested that mandatory training should be made available at all levels in public agencies (including security guards, cleaners, managers, directors and executives). Training should be continually offered periodically in view of labour turnover and 'top-up' or 'refresher' courses could be provided if people want to refresh their knowledge. Some suggested different pathways could be provided for different people such as operational staff, managers, senior managers and heads of departments. A basic program of training should be available to all, but the higher that one progresses through an organisation, the more intense and detailed the training should be to reflect policy documents and mission statements:

I would like to have in all organisations a mandated policy on forced marriages and honourbased violence in the same way you have domestic violence policies or child abuse policies or race relations policies. All organisations in all sectors - you are looking at managers, managing staff, trainers, anyone who deals with young people and the public should be required to have mandatory policies on forced marriages and honour-based violence because they are in close proximity to potential victims and could potentially come into contact with such victims (SouthAsian Female Support Worker).

\section{There is No Strategy on HBV and Forced Marriages in School Education}

Given that HBV disproportionately affects young women between the ages of 16-24, education on such issues should be embedded within the National Curriculum. However, participants criticised the fact that education on HBV had still not been embedded within the Curriculum. Many of the participants called for educational programmes to be included within schools as they felt that not enough was being done 
to educate young people. Some recommended interactive-based approaches that

include student-orientated interaction (such as role plays), delivered by those of a

similar age and discussing scenarios concerning positive relationships:

If you identify these things for children, they will learn what is right and what is wrong. Children will then act as a guard against themselves, so they won't become a victim themselves. And also it might help to identify things that are wrong for their peers, if there is a friend in need, and to know what to do if a situation like that arises (South-Asian Female Support Worker).

In terms of education, that is the key...you need to work with Key Stage I and Key Stage II, you need to work with primary school kids, kindergarten kids, in high schools, raising the levels of understanding, changing and identifying what is an abusive relationship for them, giving them role models, lots of peer-to-peer work, I never go into a school anymore, why would they want to listen to a guy in a suit? What they would prefer is to hear this from a 16-year-old person, another kid their age, encouraging younger people to go into educational institutions and share messages and share learning. But I think that is the key piece of work. The ideal scenario would be amendments to the curriculum...[support organisation] always go into schools all of the time and I keep telling [them]: 'Don't, send a kid in there, train up a group of teenagers to do this work on your behalf', the Swedish do this really well, the [Sharaf Heroes] Project, where they have got all these [male] late teens to go into schools, that's what they should be doing. And we've got to deal with that at that stage, that's my key piece, my dream (South-Asian Male Crown Prosecutor).

Survivors shared similar views about educating younger people in schools as part of the National Curriculum:

...I look back and I think: 'My friends went through all that because their dads were like my dad'. And like most of my friends who I went to school with, they're all married with like, their cousin or someone from Pakistan, they've got kids, or a few of them are divorced, because, you know, that's, nobody brings out that message across to us, even when I was young, I didn't know anything about this and if my friends did, they probably wouldn't have gone through some of the things they have in their life. There should be more of a drive in schools. Definitely in secondary schools. Primary school kids, they're a bit too young, they won't really understand it. But secondary school, I think, yeah, definitely (Survivor).

One survivor carries out voluntary in a local children's centres and youth clubs to inform women and children about the availability of support networks:

...one of the local children's centre has already allowed me to run these sessions, where it's just been coffee mornings. And these women are coming in where husbands aren't suspicious: 'Where are you?' - 'Oh, I've got to be at the school for 2 and a half hours in the play group because they're having some play sessions there'. They're happy with that, not knowing that those play sessions are places where I'm actually going in for half an hour and saying that: 'If there is anything you want to discuss', I mean, there's possibly been out of the group of twenty or so women who have been attending, three disclosures, well Alhumdulillah [thank God] which we've extracted, which before there might not have been other means. So even with the manager 
of the nursery, she's seen the results, something we need to look at ongoing. And that's what's needed...raising awareness like that, places like Youth Clubs, places where children, after school clubs, or even breakfast clubs, and as I mentioned, coffee mornings, where not only you've got your mothers being educated and being given, sort of, information and sort of breathing space, but even the children are supported as well (Survivor).

Key agents also suggested that raising awareness should be pursued within colleges and universities:

The [name of university] has a high number of referrals of forced marriages and honour-based violence - they need to have far more people involved as a support worker and as a client service, and not rely on small dedicated, often just one or two, members of staff. Staff need to be trained. Not one single specialist. You need more than one. Look at who your first aider is, we don't have one for the whole organisation, you have a designated first aider within each department, within each team, by analogy, honour-based violence should work on the same principle (South-Asian Female Support Worker).

As part of its policies, universities and other organisations could have mandatory policies that include watching a 30-minute video on forced marriages and honour-based violence. It's not asking much for a slot of time to raise awareness on these issues. It could potentially save a person's life. It is part of a duty of care towards students. All it takes is one student to trigger the rewards of having such a policy and it helps to give staff the confidence to effectively respond to such issues. This needs to be undertaken and be mandatory right across the board for people who work with young people and members of the public, lecturers, receptionists, administrators, security, right across the board...(South-Asian Female Support Worker).

You need to start the process of training, induction on honour-based violence and forced marriage awareness-raising all over again. Have a rolling programme. Such a program does not have to be delivered by a specific person in a post. It should be delivered... as part of a 'service', but is delivered by a whole group of individuals... If a victim contacts security at the university library, instead of security contacting [name of key agent] all of the time, security should be able to deal with the issue themselves because you are losing valuable time. There should be two honour-based violence, forced marriage and domestic violence representatives in each school, so that security know where they are, students know where they are...(South-Asian Female Support Worker).

\section{There is a Lack of Public Awareness Campaigns in Local Communities}

Participants also suggested that the public must have better awareness and of the specialist organisations that can help. Survivors recommended HBV support organisations should promote their profiles through the good work that they undertake more, as this can encourage victims to come forward. Many victims lead isolated lives and do not always know what organisations they can approach:

Where I got the domestic violence number was from my baby's Red Book...the only information that they had on there was the domestic violence unit and that's the one that I rung because I had no clue what to do...It was the Red Book, cos my son's appointment was the 
same week. At the back of it was a little sticker that said, you know, domestic violence unit. I thought: 'Well, you know, you can't get worse than this, this is domestic violence' (Survivor).

Another survivor who spontaneously made a decision to leave the family home agreed that victims do have lack of knowledge. She admitted that she did not know what to do or who to contact and that, as a result, she had even contemplated suicide:

I didn't know where I was going, I didn't have any friends who I could ask, cos I lived my life so isolated, I wasn't allowed out, I wasn't allowed to do anything. So I didn't even know who I could ask...I think the main thing for me is, when I was in [city], I didn't know nothing about forced marriage, honour-based violence, a refuge. I didn't even know what a refuge was, so the main thing I would say is awareness, like, not a lot of people do know a lot out there... I remember that day when I left, I thought: 'If I can't find anything, then fuck it I'm just gonna jump off [a bridge], that's it'. Cos you don't know what to do, you don't know where to go, and I think awareness is the most important thing. (Survivor).

Key agents also recommended a variety of publicity campaigns, radio shows, television, posters, stickers, campaigns in Outreach Centres and visiting community groups to maximise publicity on $\mathrm{HBV}$ :

Charity events at [support organisations] and plays inform women about the real-life situations and dangers that exist out there...Charity events and plays like this empowers women and tells them what to do when they are faced with a situation (South-Asian Female Support Worker).

One woman said she is not allowed to go outside, but she can come to a course because she is able to earn some money - a sewing class - so by becoming available in places where a lot of Asian women are able to go to, you will be able to maximise the number of people you can access who may need referral and support services. Running courses in those venues is another route to getting access to women who need help and are able to come into contact with support organisations and seek help that they may not be able to access at other times. There is also annual day trips organised by [support organisation] and we get quite a lot of referrals from there. These trips raise awareness of [support organisation] and tell people what the organisation is about (South-Asian Female Support Worker).

\section{Discussion}

This study confirms key professionals in the UK are struggling with how to respond to HBV despite the main recommendations in the HCHAC Report. What is concerning is that BME women experiencing HBV (like those experiencing domestic violence) still suffer discrete forms of discrimination by state agencies that contribute to their sense of 'double victimisation' (Razack, 1998; Gill, 2004). Participants in this study 
highlighted pockets of inconsistent responses that were inappropriate and culturally insensitive to the needs of BME women, which persuaded some to go back to abusive relationships. Lack of communication was also a barrier to accessing services and a lack of interpreters made disclosure very difficult. A failure to recruit more bilingual workers may prevent BME women from coming forward in the future and this issue may become more pertinent as $\mathrm{HBV}$ casework is increasingly passing to generic organisations that are not specialist or who lack bilingual workers. It was clear from the transcripts that survivors valued organisations that spoke the same language and understood their cultural needs, which made them feel more comfortable to disclose their experiences and seek intervention.

Criticism in particular was levelled at the UK police, health and social care services, supporting existing research that public agencies and the lower ranks of police still continue to lack important knowledge on HBV and how they should respond to victims (Begikhani et al, 2015, pp. 155-156; Hester et al, 2015; HMIC, 2015). It indicates that public agencies do not yet have a sound grasp of the nature or magnitude of $\mathrm{HBV}$, nor how best to respond to it whether initially or in the following days or weeks after a report of abuse (HMIC, 2015, p. 6 and p. 125). There were instances where state agencies did not respond appropriately to initial contact (either at the police station or social service desk) or did not treat the whereabouts of victims with strict confidentiality The lack of understanding demonstrates a lack of appropriate training and it raises the suggestion whether the UK criminal justice system can really cope with HBV at the moment. Furthermore, the domestic violence framework will not always work for HBV and in those cases where HBV presents itself more as organised crime networks with multiple perpetrators (Idriss, 2016). Intervention thus requires support for victims to be outside their family/community networks to ensure their safe 
extraction. Certain forms of intervention will have unintended negative consequences and some victims could receive poor responses if they are not taken seriously or their situations trivialised because professionals trained to address domestic violence are illprepared to respond to HBV that involve multiple perpetrators, who are prepared to track and kill their victims (Idriss, 2016). Responses to HBV therefore require specific and bespoke approaches depending on individual cases (Eshareturi et al, 2014, pp. 374375; HMIC, 2015, p. 130). More effective multi-agency practice is therefore needed to address HBV. One example concerning good practice involved one local council undertaking double/triple referral when confronted with HBV cases. This involved referring cases simultaneously to multiple agencies, such as the police and support organisations, to ensure risks are properly assessed and identified. But participants recommended the police still must improve their training and how to deal with HBV as they were singled out for showing a lack of a consistent response. Basic errors illustrate that the police still need to raise their level of knowledge (Begikhani et al, 2010, p. 118).

This study builds upon existing research that all professionals and public agencies (other than the police) must receive appropriate training and guidance about HBV in order to improve victim support (Begikhani et al, 2015). Key agents explained that despite the extensive discussions on the subject within the past two decades, individuals are still ignorant, surprised and lack knowledge about HBV and forced marriages. Survivors in particular felt let down by hospitals, GPs, local government departments, housing, social services and generic refuges. It is telling that some BME women felt that they had to return home because doctors and nurses did not seek disclosures or that refuges could not accommodate their needs. Feeling 'uncomfortable' with public agency responses was another barrier to successful intervention and more 
effort is needed to improve BME women's comfort with public services. BME women already find it very difficult to disclose abuse with the cultural expectations and 'shame' associated with leaving a husband, which can weigh heavily against their decision to leave. Religion and cultural expectations are bound up and intersect with the identities of South-Asian women and some will prefer to tolerate abuse rather than suffer the indignation of having 'lager spilt' over them. Given that issues concerning culture and religion form part of BME women's identities, those who are religiously observant will experience feelings of further distress, anxiety and shame if public agencies do not meet their needs. This will lead some to feel they are being treated with lack of dignity and respect, as well as feelings of lessened value and a sense of 'double victimisation' (Razack, 1998; Gill, 2004). Services must therefore be culturally sensitive and readily accessible. With regards to healthcare, doctors and nurses in particular must be trained to spot the signs of $\mathrm{HBV}$, to understand issues surrounding izzat for BME women and to provide an opportunity to disclose violence without the presence of family members. The health sector was singled as being particularly poor at engaging with HBV victims - all of the participants narrated accounts where doctors and nurses did not make 'routine enquiries', seek disclosures and lacked general awareness on HBV and violence in South-Asian communities (Dickson, 2014).

Although the $\mathrm{HCHAC}$ reported that there is no statutory requirement for schools to educate children about $\mathrm{HBV}$ and forced marriages with the National Curriculum (HCHAC, 2008, p. 30 and p. 36), little has been done in the interim period by the government to make this an explicit requirement as a preventative measure. Given the age, nature and diversity of the student body in modern day Britain, educational establishments should be required to educate students on HBV and forced marriages and where they can access support, as they are within the age group most vulnerable to 
such violence. Worse still, participants acknowledged that some schools opt out of discussing HBV and forced marriages for the fear of stereotyping and upsetting parents. This is a concern as the schools that show resistance are likely to have large numbers of BME students. Similar to the Sharaf Heroes Project in Sweden (a group of men touring the country highlighting the wrongs of HBV), some participants suggested that there should be role-plays performed in educational establishments by pupils of the same age. This will have an important effect on other youngsters and may help to engage them and break down barriers and patriarchal attitudes that they may have been instilled with at an early age. Furthermore, if education in schools were to become mandatory, heads of schools would be unable to opt-out from teaching such subjects for the fear of upsetting communities. Political correctness should not be an excuse for failing to raise awareness amongst children and young people that their peers may experience HBV or forced marriages. Making such education mandatory will give heads the confidence they need that they have the government's support to raise such issues.

This study also supports existing research that the public lack awareness about HBV and who to approach if they become victims (Begikhani et al, 2015, p. 155). The findings indicate there is still little awareness in BME communities about the negative impact of HBV and participants recommended improvement of community education and victim-targeted marketing. Community-based initiatives for addressing and preventing HBV must be encouraged with the support of governmental funds with a view towards changing attitudes at community level (Pope, 2004, pp. 108-109; Begikhani et al, 2010, p. 136). There must be widespread feminist education on the rights of women to combat patriarchal attitudes and systems that support the subordination of women. This must include respect for women, women's right to life, 
free choice and women's right to safety and security (Mojab, 2004; Begikhani and Hague, 2013). Education programmes within communities where HBV exists need to be expanded and delivered preferably by those who come from such communities. This can be achieved by employing BME professionals such as the police, doctors, nurses, teachers and support workers to deliver such programmes to make communities more aware of their rights and duties. This form of community engagement will also help professionals to obtain information about the occurrence of HBV locally. However, this requires funding and current budget cuts threaten not only the ability to raise awareness but the very existence of specialist support organisations. The government must allocate funds to allow specialist organisations to perform this very important function. This not only includes allocating funds to set up and establish new specialist support organisations (and preventing existing ones from closing), but includes generating funds for such services to advertise on Asian television and radio stations, magazines, posters and to sponsor community day-trips and other events in order to inform their local communities that support is available.

\section{Conclusion}

Despite the publication of the HCHAC Report in 2008 that made positive recommendations to address $\mathrm{HBV}$, unfortunately eight years has passed and not all of the recommendations have been fulfilled. The UK government has, instead, been preoccupied with addressing but one aspect of HBV, namely forced marriages and has specifically created legislation criminalising such acts. Yet this has led to a situation where HBV has been left unaddressed. As a result, not-for-profit organisations have been left to raise the profile on HBV. Policies and preventative strategies of late have been lacking at a national level and this has had a negative impact on the public 
agencies' awareness and understanding of HBV. This places victims in the UK at risk, especially those whose cases are more akin to organised crime. The UK government must take responsibility for the slow development of policy specifically on HBV and it is suggested that in order to improve knowledge, better training for all public sector workers and government departments must be pursued; it must be a mandatory requirement to educate young people in schools about HBV and forced marriages; and more funds must be allocated for specialist organisations to promote their services and to engage with their local communities in information campaigns about the work they do. Will training and awareness really provide an appropriate response to HBV and is research available to show that it can help? There is generally a lack of empirical research on the success of preventative/community-based programs proven effective at preventing crime and many of those that have been undertaken have been conducted in schools aimed at addressing youth behaviour and violence (Whitaker et al, 2006). Nevertheless, those school studies have shown that short, coherent and thoroughly prepared interventions, culturally sensitive, sensitively conducted and supported by pastoral support and delivered over a period of weeks can improve knowledge and reduce young people's acceptance of domestic violence (Whitaker et al, 2006, p. 160161; Hague and Bridge, 2008, pp. 187, 192-193; Gadd et al, 2014, p. 476). There is no reason why this could not extend to HBV and forced marriages. Awareness raising in school settings also have a number of advantages and are often ideal for interventions of this nature because a large number of students can be easily reached (Whitaker et al, 2006: 162). Furthermore, additional studies have been positive in their conclusions about community/prevention-based models that affect particular minority groups outside of the school arena (Pan et al, 2006). This is because such initiatives help to denounce intra-familial violence, promote egalitarian attitudes and behaviour and 
encourage community members to confront abusive behaviour (Yoshihama et al, 2012; Yoshihama et al, 2014). The UK government must therefore continue the good work undertaken by the HCHAC and ensure these recommendations are implemented if the desire to support victims of $\mathrm{HBV}$ is genuine and for there to be significant progress made in preventing $\mathrm{HBV}$ in the future.

\section{References}

Akinpar, A. (2003). The Honour/Shame Complex Revisited: Violence Against Women in the Migration Context. Women's Studies International Forum, 26(5), 425-442.

Anitha, S (2008). Forgotten Women: Domestic Violence, Poverty and South Asian Women with No Recourse to Public Funds. Manchester: Oxfam Publishing.

Anitha, S. and Gill, A. K. (2011). The Social Construction of Forced Marriage and its

'Victim' in Media Coverage and Crime Policy Discourses. In Gill, A. K. and Anitha, S. (Eds.), Forced Marriage: Introducing a Social Justice and Human Rights Perspective, (pp. 112-134). London: Zed Books.

Anitha, S., and Gill, A. K. (2015). A Moral Panic? The Problematization of Forced Marriage in British Newspapers, Violence Against Women, 21(9), 1123-1144.

Begikhani, N., Gill, A., and Hague, G. (2010). Final Report-Honour-Based Violence $(H B V)$ and Honour-Based Killings in Iraqi Kurdistan and in the Kurdish Diaspora in the UK. University of Bristol. 
Begikhani, N., and Hague, G. (2013). Honour-Based Violence: Moving Towards Action in Iraqi Kurdistan. The Copernicus Journal of Political Studies, 2(4), 211-221.

Begikhani, N., Gill, A. K., and Hague, G. (2015). Honour-Based Violence Experiences and Counter-Strategies in Iraqi Kurdistan and the UK Kurdish Diaspora. London: Ashgate.

Burman, E., Smailes, S. L. and Chantler, K. (2004). 'Culture' as a Barrier to Service Provision and Delivery: Domestic Violence Services for Minoritized Women. Critical Social Policy, 24(3), 332-357.

Chantler, K. (2006). Independence, Dependency and Interdependence: Struggles and Resistances of Minoritized Women Within and on Leaving Violent Relationships. Feminist Review, 82, 27-49.

Crenshaw, K. (1989). Demarginalizing the Intersection of Race and Sex: A Black Feminist Critique of Antidiscrimination Doctrine, Feminist Theory and Antiracist Politics. University of Chicago Legal Forum, 139-167.

Crown Prosecution Service (CPS). (2008). CPS Pilot on Forced Marriage and SoCalled Honour Crime - Findings. London. December 2008.

Dickson, P. (2014). Understanding Victims of Honour-Based Violence. Community Practitioner, 87(7), 30-33. 
Dobash, R. E., and Dobash, R. (1979) Violence Against Wives - A Case Against the Patriarchy. New York: The Free Press.

Eshareturi, C., Lyle, C., and Morgan, A. (2014). Policy Responses to Honor-Based Violence: A Cultural or National Problem? Journal of Aggression, Maltreatment and Trauma, 23(4), 369-382.

Home Office, Forced Marriage Unit Statistics 2015, 8 March 2016.

Gadd, D., Fox, C. L., and Hale, R. (2014). Preliminary Steps Towards a More Preventative Approach to Eliminating Violence Against Women in Europe. European Journal of Criminology, 11(4), 464-480.

Gangoli, G., Chantler, K., Hester, M., and Singleton, A. (2011). Understanding Forced Marriage: Definitions and Realities. In Gill, A. K. and Anitha, S. (Eds.), Forced Marriage: Introducing a Social Justice and Human Rights Perspective (pp. 25-45). London: Zed Books.

Gill, A. (2004). Voicing the Silent Fear: South Asian Women's Experiences of Domestic Violence. Howard Journal of Criminal Justice, 43(5), 465-483.

Gill, A. (2010). Reconfiguring 'Honour-Based Violence as a Form of Gendered Violence'. In Idriss, M. M. and Abbas, T. (Eds.), Honour, Violence, Women and Islam (pp. 218-231). London: Routledge-Cavendish. 
Gill, A. K. (2011). Exploring the Viability of Creating a Specific Offence for Forced Marriage in England and Wales: Report on Findings. University of Roehampton. July.

Gill, A. (2012). 'Honour-Based Violence Runs Deep and Wide', The Guardian, 1 February 2012.

Gill, A. K., Strange, C. and Roberts, K. (Eds.). (2014). Honour Killing and Violence: Theory, Policy and Practice. Hampshire: Palgrave MacMillan.

Gill, A. K. (2014). Introduction: 'Honour' and 'Honour'-Based Violence: Challenging Common Assumptions. In Gill, A. K. Strange, C. and Roberts, K. (Eds.), Honour Killing and Violence: Theory, Policy and Practice (pp. 1-26). Hampshire: Palgrave MacMillan.

The Guardian (2015). Businessman is First Person Jailed Under Forced Marriage Laws, 10 June 2015.

Gupta, R. (Ed.). (2003). From Homebreakers to Jailbreakers: Southall Black Sisters. London: Zed Books.

Hague, G. and Bridge, S. (2008). Inching Forward on Domestic Violence: The 'CoOrdinated Community Response' and Putting it in Practice in Cheshire. Journal of Gender Studies, 17(3), 185-199. 
Her Majesty's Inspectorate of Constabulary (HMIC). (2014). Everyone's Business: Improving the Police Response to Domestic Abuse. Report, 27 March 2014.

Her Majesty's Inspectorate of Constabulary (HMIC). (2015). The Depths of Dishonour: Hidden Voices and Shameful Crimes. Report, 8 December 2015.

Hester, M., Gangoli, G., Gill, A. K., and Mulvihill, N. (2015). Victim/Survivor Voices - A Participatory Research Project (Report for HMIC HBV Inspection), 31 August 2015, University of Bristol.

Home Office. 2012. Forced Marriages - A Consultation, Summary of Responses, June.

House of Commons Home Affairs Committee. 2008. Domestic Violence, Forced Marriage and 'Honour'-Based Violence, Sixth Report of Session 2007-08, Volume I, 13 June 2008, HC 263-I.

House of Commons Home Affairs Committee. 2011. Forced Marriage (Eighth Report of Session 2010-12, 17 May 2011, HC 880).

Idriss, M. M. and Abbas, T. (Eds.). (2010). Honour, Violence, Women and Islam. London: Routledge-Cavendish.

Idriss, M. M. (2015). Forced Marriages - The Need for Criminalisation?. Criminal Law Review, 9, 687-703. 
Idriss, M. M. (2016). Not Domestic Violence or Cultural Tradition: Is HBV Distinct From Domestic Violence? Journal of Social Welfare and Family Law (Forthcoming)

Izzidien, S. (2008). 'I Can't Tell People What is Happening at Home'. Domestic Abuse within South Asian Communities: The Specific Needs of Women, Children and Young People. NSPCC Inform.

Johal, A. (2003). Struggle Not Submission: Domestic Violence in the 1990s. In Gupta, R. (Ed.), From Homebreakers to Jailbreakers: Southall Black Sisters (pp. 28-50). London: Zed Books.

Julios, C. (2015). Forced Marriage and 'Honour' Killings in Britain - Private Lives, Community Crimes and Public Policy Perspectives. Surrey: Ashgate.

Kelly, L. (1988). Surviving Sexual Violence. Oxford: Polity Press.

Meeto, V., and Mirza, H. S. (2010). There is Nothing 'Honourable' about Honour Killings - Gender, Violence and the Limits of Multiculturalism. In Idriss, M. M. and Abbas, T. (Eds.), Honour, Violence, Women and Islam (pp. 42-66). London: RoutledgeCavendish.

Metlo, Z. (2012). The Perception of Honour Among the British-Pakistani Community in Watford, United Kingdom. PhD Thesis: University of Leeds. April 2012. 
Ministry of Justice. (2009). One Year On: The Initial Impact of the Forced Marriage (Civil Protection) Act 2007 in its First Year of Operation, November.

Mojab, S., and Abdo, N. (Eds.). (2004). Violence in the Name of Honour: Theoretical and Political Challenges. Istanbul: Istanbul Bilgi University Press.

Mojab, S. (2004). The Particularity of 'Honour' and the Universality of 'Killing'. In S. Mojab and N. Abdo (Eds.), Violence in the Name of Honour: Theoretical and Political Challenges (pp. 15-38). Istanbul: Istanbul Bilgi University Press.

Ortner, S. (1978). The Virgin and the State. Feminist Studies, 4, 19-35.

Pan, A., Daley, S., Rivera, L. M., Williams, K., Lingle, D. and Reznik, V. (2006). Understanding the Role of Culture in Domestic Violence: The Ahimsa Project for Safe Families, Journal of Immigrant and Minority Health, 8(1), 35-43.

Pope, N. (2004). Honour Killings: Instruments of Patriarchal Control. In S. Mojab and N. Abdo (Eds.), Violence in the Name of Honour: Theoretical and Political Challenges (pp. 101-112). Istanbul: Istanbul Bilgi University Press.

Rai, D. K., and Thiara, R. K. (1997). Redefining Spaces: The Needs of Black Women and Children and Black Workers in Women's Aid. Bristol: Women's Aid Federation England. 
Razack, S. H. (1998). What is to be Gained by Looking White People in the Eye? Race in Sexual Violence Cases. In Razack, S. (Ed.), Looking White People in the Eye: Gender, Race, and Culture in Courtrooms and Classrooms (pp. 56-87). Toronto: University of Toronto Press.

Reddy, R. (2008). Gender, Culture and the Law: Approaches to Honour Crimes in the UK, Feminist Legal Studies, 16(3), 305-321.

Reddy, R. (2014). Domestic Violence or Cultural Tradition? Approaches to 'Honour Killing' as Species and Subspecies in English Legal Practice. In Gill, A. K., Strange, C., and Roberts, K. (Eds.), Honour Killing and Violence: Theory, Policy and Practice (pp. 27-45). Hampshire: Palgrave MacMillan.

Reimers, E. (2007). Representations of an Honor Killing - Intersections of Discourses on Culture, Gender, Equality, Social Class and Nationality', Feminist Media Studies, 7(3), 239-255.

Rennison, C., and Planty, M. (2003). Non-Lethal Intimate Partner Violence: Examining Race, Gender and Income Patterns. Violence and Victims, 18(4), 433-443.

Sokoloff, N. J. and Dupont, I. (2005). Domestic Violence at the Intersections of Race, Class and Gender. Violence Against Women, 11(1), 38-64. 
Sen, P. (2005) “Crimes of Honour", Value and Meaning'. In Welchman, L. and Hossein, S. (Eds.), 'Honour' - Crimes, Paradigms, and Violence Against Women (pp. 42-63). London: Zed Books.

Siddiqui, H. (2005). There is No 'Honour' in Domestic Violence, Only Shame! Women's Struggles Against "Honour" Crimes in the UK. In Welchman, L. and Hossein, S. (Eds.), 'Honour' - Crimes, Paradigms, and Violence Against Women (pp. 263-281). London: Zed Books.

Sirman, N. (2004). Kinship, Politics and Love: Honour in Post-Colonial Contexts - The Case of Turkey. In Mojab, S., and Abdo, N. (Eds.), Violence in the Name of Honour: Theoretical and Political Challenges (pp/ 39-56). Istanbul: Istanbul Bilgi University Press.

Thiara, R. K., and Gill, A. K. (2010). Understanding Violence Against South Asian Women. In Thiara, R. K., and Gill, A. K. (Eds.), Violence Against Women in South Asian Communities (pp. 29-54). London: Jessica Kingsley.

Welchman, L., and Hossein, S. (Eds). (2005). 'Honour': Crimes, Paradigms and Violence Against Women. London: Zed Books.

Whitaker, D. J., Morrison, S., Lindquist, C., Hawkins, S. R., O’Neil, J. A., Nesius, A. M., Mathew, A. and Reese, L. (2006). A Critical Review of Interventions for the Primary Perpetration of Partner Violence. Aggression and Violent Behavior, 11, 151166. 
Wilson, A. (1978). Finding a Voice: Asian Women in Britain. London: Virago Press.

Wilson, A. (2006). Dreams, Questions, Struggles: South Asian Women in Britain. London: Pluto Press.

Wilson, A. (2010). Charting South Asian Women's Struggles Against Gender-Based Violence. In R. K. Thiara and A. Gill (Eds.), Violence Against Women in South Asian Communities (pp. 55-79). London: Jessica Kingsley.

Yoshihama, M., Ramakrishnan, A., Hammock, A. C. and Khaliq, M. (2012). Intimate Partner Violence Prevention Program in an Asian Immigrant Community: Integrating Theories, Data and Community. Violence Against Women, 18(7), 763-783.

Yoshihama, M., Blazecski, J. and Bybee, D. (2014). Enculturation and Attitudes Towards Intimate Partner Violence and Gender Roles in an Asian Indian Population: Implications for Community-Based Prevention. American Journal of Community Psychology, 53, 249-260.

Zosky, D. (2011). A Matter of Life and Death: The Voices of Domestic Violence Survivors. Journal of Women and Social Work, 26(2), 201-212. 